\title{
Occurrence, chemistry, and origin of immiscible silicate glasses in a tholeiitic basalt: A TEM/AEM study
}

\author{
Lung-Chuan Kuo*, Jung H. Lee**, Eric J. Essene, and Donald R. Peacor \\ Department of Geological Sciences, University of Michigan, Ann Arbor, MI 48109, USA
}

\begin{abstract}
The occurrence and chemistry of immiscible silicate glasses in a tholeiite mesostasis from the Umtanum formation, Washington, were investigated with transmission electron microscopy and analytical electron microscopy (TEM/AEM). TEM observation reveals isolated, dark globules (2.1 micron or less in diameter) randomly distributed in a transparent matrix glass interstitial to plagioclase laths. The globules less than 0.3 micron and larger than 0.8 micron fall beyond the linear relationship defined by the $0.3-0.8$ micron globules in a plot of the logarithm of number versus size. Large globules $(0.7$ micron or larger in diameter) range from homogeneous to heterogeneous in optical properties and chemistry. Homogeneous globules are completely glassy, whereas heterogeneous globules contain crystalline domains. AEM analyses show that the globules have high $\mathrm{Si}, \mathrm{Fe}, \mathrm{Ca}$, and $\mathrm{Ti}$ with subordinate $\mathrm{Mg}$, $\mathrm{Al}, \mathrm{P}, \mathrm{S}, \mathrm{Cl}, \mathrm{K}$, and $\mathrm{Mn}$, which gives high normative $f a$, $p x$, il, and ap. The matrix glass consists dominantly of $\mathrm{Si}$ with low $\mathrm{Al}$ and minor $\mathrm{Na}$ and $\mathrm{K}$, yielding a high normative $q z$, or, $a b$, and $a n$.

It is proposed that the silicate liquid immiscibility occurs by reaction of network-modifying cations (NMCs) with dominantly chain-like anionic units in the parental melt to form less polymerized, NMC-bearing units and highly polymerized, Si-rich units. The globules nucleated metastably under supercooled conditions, and medium-size globules become either larger or smaller at lower temperatures. Internal nucleation of NMC-rich phases occurred in some larger globules upon cooling.
\end{abstract}

\section{Introduction}

The immiscibility of silicate liquids has received considerable attention in igneous petrology and in ceramic sciences. Stable and metastable immiscibility fields have been discovered in many glass-forming systems (see Levin (1970) for a review). In igneous petrology, although their implication on petrogenesis of silicate rocks is still disputed, the occurrence, chemistry, and phase relations of immiscible liquids have been studied extensively in both lunar and terrestrial basalts and experimentally in multicomponent sili-

\footnotetext{
* Present address and address for offprint requests: Exploration Research and Development Division, Conoco Inc., Ponca City, OK 74603, USA

** Present address: Department of Geology, Chonbuk National University, Chonju, Korea 520
}

cate systems (Roedder 1979; Philpotts 1982). Silicate liquid immiscibility has also been discussed in light of melt structure (Hess 1980) and thermodynamics (Charles 1969).

Although naturally occurring immiscible glasses are well known in terms of their chemistry, no conclusive studies have been made on the physical processes and mechanisms involved in liquid immiscibility in igneous systems. The kinetics of immiscibility have been demonstrated to be better understood with TEM studies (Ohlberg and Hammel 1965; James and McMillan 1970; Burnett and Douglas 1970). The immiscible glasses in the present study are suitable for AEM analysis because they are typically micron-sized, which approaches the limit of microprobe investigation.

In this paper, we report and discuss the results of a first TEM/AEM study on the immiscible glasses in a natural tholeiite. The detailed observation of submicroscopic features in these glasses and comparison of AEM analyses with microprobe data on other similar immiscible glasses were made, and the conditions and physical processes involved in the formation of immiscible liquids evaluated.

\section{General petrography}

The Umtanum formation of the Columbia River Basalt is composed of several units of tholeiitic lava flows with a total thickness of approximately $70 \mathrm{~m}(923-990 \mathrm{~m}$ below the surface of the Pasco Basin area, Washington; Myers et al. 1979). The samples subjected to the present study are from the $938.2-938.5 \mathrm{~m}$ level of the well DC-6 at Hanford Site, Washington. These dark gray tholeiites have a fine-grained, homogeneous lithology. In thin section, these rocks display a hyalo-ophitic texture characterized by the presence of abundant plagioclase laths (typically on the order of $0.01 \mathrm{~mm}$ in width), less abundant, subequant augite grains (approximately $0.01 \mathrm{~mm}$ across), and a small amount of olivine microphenocrysts in a matrix composed of immiscible glasses. Plagioclase laths frequently show flow lineation. Plagioclase phenocrysts (approximately $0.1 \mathrm{~mm}$ in width) are occasionally present, whereas titanomagnetite grains (approximately $0.02 \mathrm{~mm}$ across, many show hopper or skeletal morphology) are ubiquitous. Alteration of olivine, augite, and glass is localized along the fracture contacts. Spherical to ellipsoidal vesicles are occasionally present, and some large vesicles are filled with zeolites. The bulk composition of this tholeiite unit is given in Table 1.

\section{Sample preparation}

Double-polished thin sections were prepared using a heat-sensitive crystal-bond as the adhesive. Upon microscopic observation, appropriate areas were selected and enclosed by aluminum washers ( $3 \mathrm{~mm}$ o.d., $1.5 \mathrm{~mm}$ i.d., and $0.25 \mathrm{~mm}$ thick) epoxied to the surface 
Table 1. The bulk composition of the Umtanum basalt and the AEM analyses of globules and matrix glasses

\begin{tabular}{|c|c|c|c|c|c|c|c|}
\hline & \multirow[t]{2}{*}{ Host rock } & \multicolumn{2}{|c|}{ Homogeneous globules } & \multicolumn{2}{|c|}{ Heterogeneous globules } & \multicolumn{2}{|c|}{ Matrix glasses } \\
\hline & & 1 & 2 & 3 & 4 & 5 & $6^{\mathrm{a}}$ \\
\hline $\mathrm{SiO}_{2}$ & 53.14 & 29.8 & 30.0 & 36.1 & 32.0 & 77.5 & 65.6 \\
\hline $\mathrm{TiO}_{2}$ & 2.12 & 6.4 & 6.8 & 1.0 & 8,9 & 1.0 & 0.9 \\
\hline $\mathrm{Al}_{2} \mathrm{O}_{3}$ & 12.84 & 0.8 & 1.0 & 2.1 & 1.6 & 14.4 & 17.2 \\
\hline $\mathrm{Fe}_{2} \mathrm{O}_{3}$ & 3.62 & & & & & & \\
\hline$\sum \mathrm{FeO}$ & 11.06 & 47.4 & 43.1 & 34.2 & 36.4 & 1.9 & 3.1 \\
\hline $\mathrm{MnO}$ & 0.22 & 0.7 & 0.4 & 0.4 & $\operatorname{tr}$ & nd & nd \\
\hline $\mathrm{MgO}$ & 3.65 & 0.8 & 1.0 & 2.7 & $\operatorname{tr}$ & $\operatorname{tr}$ & $\operatorname{tr}$ \\
\hline $\mathrm{CaO}$ & 7.11 & 10.3 & 11.0 & 15.9 & 14.4 & 1.5 & 3.7 \\
\hline $\mathrm{Na}_{2} \mathrm{O}$ & 3.15 & nd & nd & nd & nd & 1.2 & 4.4 \\
\hline $\mathrm{K}_{2} \mathrm{O}$ & 1.39 & $\operatorname{tr}$ & $\operatorname{tr}$ & 0.3 & 1.0 & 2.4 & 5.1 \\
\hline $\mathrm{P}_{2} \mathrm{O}_{5}$ & 0.33 & 3.2 & 5.7 & 7.3 & 5.7 & nd & nd \\
\hline $\mathrm{SO}_{2}$ & & 0.6 & 1.0 & nd & nd & nd & nd \\
\hline $\mathrm{H}_{2} \mathrm{O}^{-}$ & 1.05 & & & & & & \\
\hline \multicolumn{8}{|c|}{ CIPW norms (wt \%) for $\mathrm{Fe}^{3+} / \mathrm{Fe}^{2+}=0.1$} \\
\hline Q & 7.84 & & & & 0.8 & 57.5 & 12.4 \\
\hline or & 8.43 & & & 1.7 & 5.9 & 14.2 & 30.1 \\
\hline$a b$ & 27.36 & & & & & 10.2 & 37.2 \\
\hline an & 17.13 & 2.2 & 2.7 & 4.8 & 1.4 & 7.4 & 12.1 \\
\hline $\mathrm{C}$ & & & & & & 7.1 & \\
\hline di & 6.50 & 0.8 & 0.6 & 2.9 & & & \\
\hline hd & 7.66 & 24.1 & 12.4 & 20.0 & 29.1 & & 5.6 \\
\hline en & 6.31 & 0.5 & 1.9 & 4.8 & & & \\
\hline fs & 8.53 & 18.1 & 43.0 & 38.0 & 27.3 & 1.4 & 0.4 \\
\hline fo & & 0.7 & 0.2 & 0.4 & & & \\
\hline $\mathrm{fa}$ & & 26.6 & 5.9 & 3.4 & & & \\
\hline $\mathrm{mt}$ & 5.35 & 6.9 & 6.2 & 4.9 & 5.3 & 0.3 & 0.5 \\
\hline il & 4.09 & 12.1 & 12.9 & 1.9 & 16.8 & 1.9 & 1.7 \\
\hline ap & 0.80 & 7.6 & 13.5 & 17.2 & 13.4 & & \\
\hline py & & 0.4 & 0.7 & & & & \\
\hline
\end{tabular}

nd: not detected; tr: only trace amount present

a contaminated by plagioclase

of the thin section. The washers with the samples were then removed by heating the thin section, and the samples were subjected to ion milling for typically about $10 \mathrm{~h}$, resulting in a circular thin edge around a hole at the center of the sample which is appropriate for TEM observation and AEM analysis. A total of 6 samples from two thin sections were prepared for the present study.

\section{Occurrence of immiscible glasses}

\section{General observation}

Typical occurrence of the immiscible glasses is illustrated in Fig. 1. This is characterized by the presence of isolated globules (black) randomly distributed in the homogeneous, transparent matrix glass (white, and gray when thicker) which is interstitial to plagioclase laths. The globules vary in size from less than 0.2 micron to as large as approximately 2 microns, with the small globules being much more abundant than the large ones (Fig. 1a). The globules (especially small ones) are generally spherical in shape, even for those very close to the plagioclase laths (Fig. $1 \mathrm{~b}$ ). This, together with the uniform population of the globules throughout the matrix glass, indicates that the globules did not form by nucleation on the existing plagioclase surfaces. In addition, no correlation between the globule size and distance from the plagioclase laths could be detected. Large globules range from homogeneous to heterogeneous in opti- cal properties. Several heterogeneous globules are indicated by arrows in Fig. 1 a.

\section{Detailed features of the globules}

The most significant feature of the globules is their wide range of optical properties under TEM observation (Fig. 2). Homogeneous globules are marked by a perfectly smooth outline with uniform image throughout the interior (3 in Fig. 2a, b). Energy-dispersive analyses in traverses across these globules indicate that they are chemically homogeneous without detectable zonation. Electron diffraction patterns reveal that they are completely glassy.

The onset of optical heterogeneity can be seen in the globules numbered 2 and 4 in Fig. $2 \mathrm{a}$ and in Fig. $2 \mathrm{c}$. The outlines of these globules are slightly ragged, and the image in the interior is no longer uniform. Furthermore, it appears that the heterogeneity is initiated along the periphery of the globule (Fig. 2c), implying that the heterogeneity is mainly caused by the nucleation of crystalline phases at the globule-matrix glass interface. Energy-dispersive spectra indicate that these glasses are chemically less homogeneous than the completely glassy globules. Electron diffraction patterns, however, indicate that these globules are noncrystalline, which may be due to the extremely low degree of crystallization and very small sizes of the nuclei.

The globule 1 in Fig. 2 a displays a higher degree of 

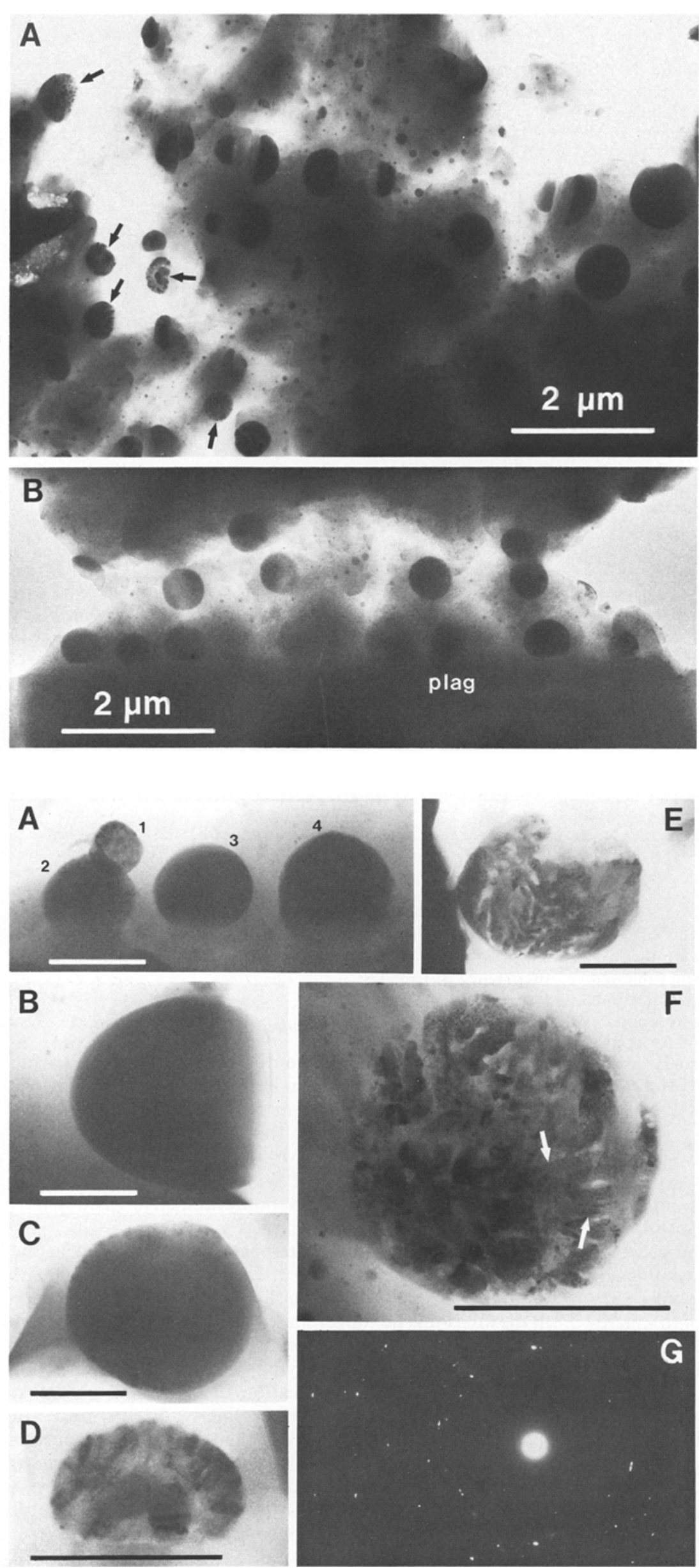

Fig. 1. TEM images showing typical occurrence of immiscible glasses in the Umtanum tholeiite.

a Randomly distributed spherical and ellipsoidal globules with various sizes and optical properties in a transparent matrix glass. Several optically

heterogeneous globules are indicated by arrows.

b Globules near a plagioclase lath (the grain horizontally oriented at the lower part of the photograph). Note the sphericity of the globules in contact with the plagioclase

Fig. 2. TEM images showing detailed features in the globules. All scale bars: 0.5 micron.

a Globules from homogeneous (3) to slightly heterogeneous ( 2 and 4 ) to heterogeneous (1).

b A perfectly homogeneous globule. Note the smooth outline and uniform contrast throughout the interior. c A slightly heterogeneous globule. Note that only the periphery of the globule shows appreciable contrast due to the presence of many small spots which are perhaps the nucleation centers of crystallites. The interior of the globule remains homogenous.

d A heterogeneous globule containing elongated domains extended towards the center from the upper edge of the globule. Two ellipsoidal domains are present at the lower center of the globule

e A heterogeneous globule showing a domain with a skeletal morphology and a ragged margin.

f A heterogeneous globule showing irregularly distributed domains. Most domains appear to be subspherical in shape. Note, however, two elongated domains (indicated by arrows) with relatively flat outlines. The domains with different shapes may be different crystalline species.

g The electron diffraction pattern, taken from the globule shown in $\mathbf{f}$, indicates pronounced crystallinity but irregular orientation of crystallites 


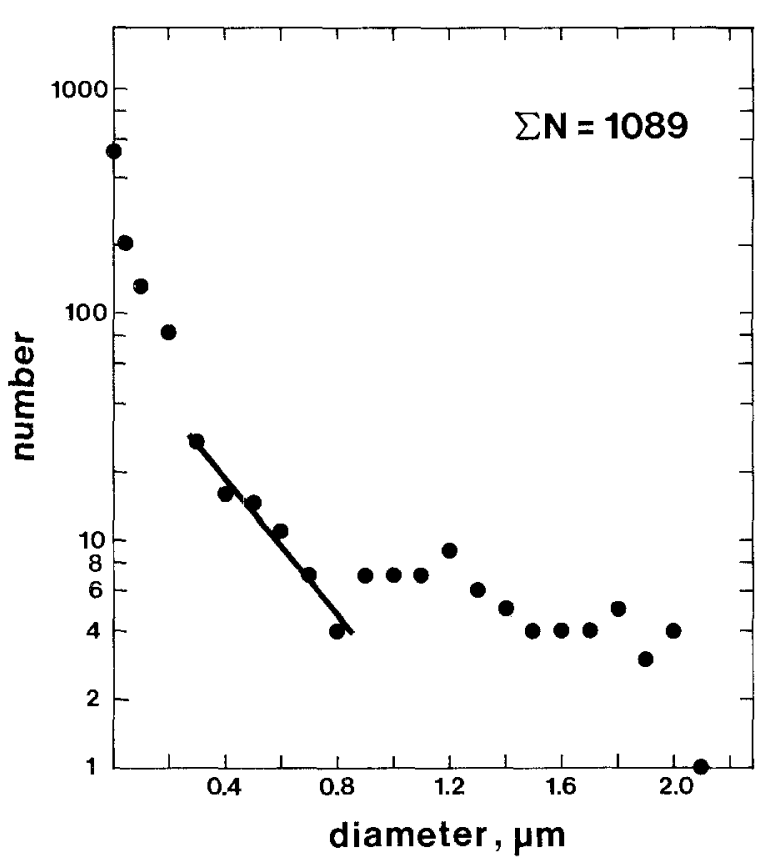

Fig. 3. Statistical size distribution of the globules. Note the welldefined linear relationship for the sizes between 0.3 and 0.8 microns (indicated by the heavy line)

optical heterogeneity than those described above, and the globules in Figs. $2 \mathrm{~d}$, e, and f show extreme heterogeneity. These heterogeneous globules are composed if irregularly sized and shaped domains of crystallites which is manifested by the irregular electron diffraction patterns (e.g. Fig. 2 g) and pronounced chemical heterogeneity of the globule as a whole. No positive identification can be made on the species of these crystallites. In one set of energy-dispersive spectra taken across a globule (Fig. 2f) a covariation between $\mathrm{Ca}$ and $\mathrm{P}$ was recognized, indicating the possible presence of apatite as one of the crystalline species. The overall sphericity of these globules suggests that the crystallites were formed by nucleation inside the originally homogeneous, glassy globules.

\section{Size distribution of the globules}

The sizes of 1089 globules from 9 TEM photographs have been measured to establish the statistics of size distribution. A maximum diameter of the circular image was adopted for each globule. This diameter must represent the true diameter of the spherical globule, because all the globules are much smaller than the thickness of the thin section (approximately 20 microns) and the globules were more resistant to ion milling than matrix glass. The sizes of globules were then grouped into 0.1-micron intervals, and the total number of globules within each size interval was plotted. For sizes of 0.1 micron or less, an interval of 0.05 micron was used.

The size of the globules ranges from less than 0.05 micron to over 2 microns, with a negative correlation between the size and the number of globules (Fig. 3). Only one globule was found larger than 2.1 microns. A linear correlation exists between the logarithm of the number and the size for the $0.3-0.8$ micron range, whereas the numbers of the globules outside this range are larger than those corresponding to this linear relationship.
Chemistry of the immiscible glasses

\section{Analytical procedure}

AEM analyses were performed in two different schemes: quantitative analysis on immiscible glasses and semiquantitative point counts for concentration gradients in the matrix glass adjacent to globules. A beam size of 0.05 micron and a point interval of 0.03-0.1 micron along a traverse were used for detecting concentration gradients in the matrix glass in areas up to 0.4 micron in thickness. Quantitative analyses, on the other hand, were carried out in relatively thin areas ( 0.2 micron thick or less) to eliminate matrix effects as encountered in microprobe analyses (Goldstein et al. 1977), and with a relatively broad beam (approximately 0.1 micron in diameter) primarily for minimizing diffusion of alkali elements ( $\mathrm{Na}$ and $\mathrm{K}$ ) during analysis (Knipe 1979; Craw 1981). Quantitative analyses were performed only on globules larger than 0.5 micron and on matrix glasses with minimal numbers of nearby small globules to avoid contamination as much as possible. The electron microscope (JEOL JEM-100CX) is equipped with a solidstate energy-dispersive $\mathrm{X}$-ray detector with an $\mathrm{X}$-ray spatial resolution of up to 0.03 micron. The instrument is operated at $100 \mathrm{kV}$ and 100 microamps.

Quantitative AEM analyses of immiscible silicate glasses were obtained following the "ratio method" (Cliff and Lorimer 1975; Lorimer and Cliff 1976). Intensity ratios between $\mathrm{Si}$ and other elements were determined by measuring the peak area defined by each element in an energy-dispersive spectrum with a planimeter (appropriate background subtracted). The concentration ratios between Si and other elements were then calculated with the relationship

$I_{i} / I_{\mathrm{Si}}=k_{i}\left(C_{i} / C_{\mathrm{Si}}\right)$,

where $I_{i}$ and $I_{\mathrm{Si}}$ are measured peak areas for an element $i$ and for $\mathrm{Si}$, respectively, and $C_{i}$ and $C_{\mathrm{Si}}$ are the concentrations of the elements $i$ and $\mathrm{Si}$ in the unknown. For any given element, a constant $k_{i}$ was calculated from an appropriate standard with accurately known composition using the same equation as described above. The calculated $C_{i}$ values and the $C_{S i}$ (equal to 1) for the unknown were then normalized to $100 \mathrm{wt} \%$. Because the count rates on thin samples are low (several tens to several hundreds $\mathrm{cps}$ ), about 10 spectra from one area were typically accumulated to obtain an analysis (Blake et al. 1983). The standards used in the present analysis were adularia $(\mathrm{Al}, \mathrm{K})$, labradorite $(\mathrm{Na}, \mathrm{Ca})$, fayalite $(\mathrm{Fe})$, clinochlore $(\mathrm{Mg})$, and sphene (Ti). The $\mathrm{k}$-values for $\mathrm{Mn}$ and $\mathrm{P}$ were estimated from the standard curve of $\mathrm{k}$-value versus atomic number for $100 \mathrm{kV}$ operating voltage (Lorimer and Cliff 1976).

Because the thickness of the samples analyzed are well within the limit of "thin film criteria" (Goldstein 1979; Zaluzec 1979), no absorption or fluorescence correction is necessary. Considerable effort was made to minimize the generation of spurious X-rays from objects other than the samples (Allard and Blake 1982). Analytical uncertainties of 1 percent relative and 5 percent relative for major and minor elements, respectively, are calculated based on counting statistics. Additional inaccuracy on the analysis of $\mathrm{Na}$ and $\mathrm{K}$ is present due to diffusion induced by the electron beam. The overall analytical error in normalized data due to these inaccuracies is estimated to be about 2 percent relative.

\section{Chemical compositions of the immiscible glasses}

The energy-dispersive spectra (Fig. 4) show that the globules are charaterized by high $\mathrm{Si}, \mathrm{Fe}, \mathrm{Ca}$, and $\mathrm{Ti}$ with subordinate $\mathrm{Mg}, \mathrm{Al}, \mathrm{P}, \mathrm{S}, \mathrm{Cl}, \mathrm{K}$, and $\mathrm{Mn}$, and the matrix glasses consist dominantly of $\mathrm{Si}$ with low $\mathrm{Al}$ and minor $\mathrm{Na}$ and $\mathrm{K}$. The presence of trace amounts of $\mathrm{Ca}, \mathrm{Ti}$, and $\mathrm{Fe}$ in the matrix glass is due to contamination by small globules, which is difficult to avoid because of the dense population of small globules throughout the matrix glass (see Fig. 1). 


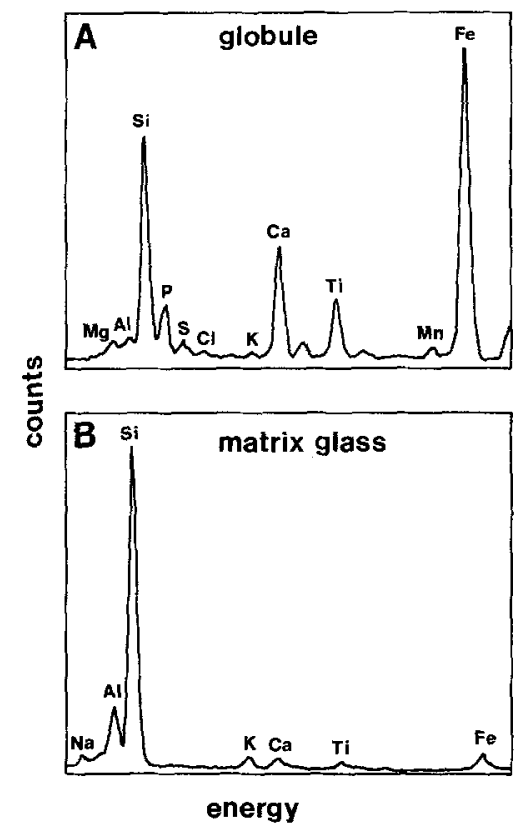

Fig. 4. Typical energy-dispersive spectra for globules (a) and matrix glasses (b)

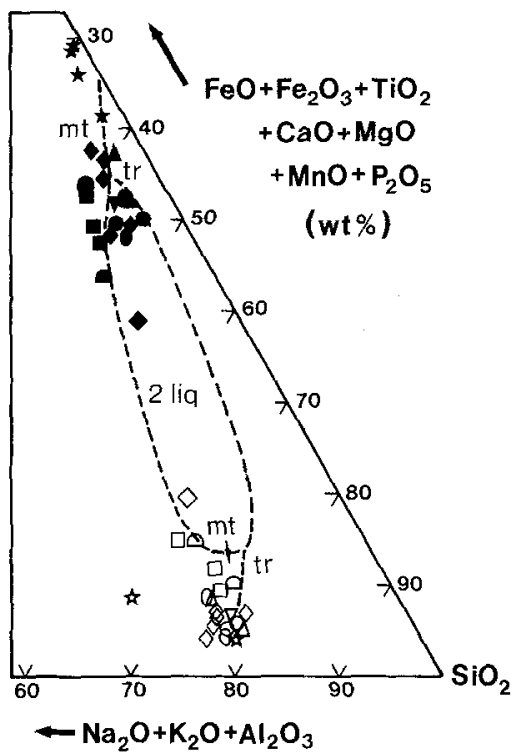

Fig. 5. Comparison of the compositions of immiscible glasses in basalts from AEM and microprobe analyses. The dashed lines are phase boundaries in the system $\mathrm{KAlSi}_{3} \mathrm{O}_{8}-\mathrm{Fe}_{2} \mathrm{O}_{3}-\mathrm{FeO}-\mathrm{SiO}_{2}$ at $\mathrm{fO}_{2}=10^{-9}$ (Naslund 1983). 2 liq: field of stable immiscibility, $\mathrm{mt}$ : magnetite, tr: tridymite. The open and solid symbols represent high-Si and high-Fe glasses, respectively. Symbols with the same pattern indicate a pair of analyses (tie-lines omitted for clarity). Stars: this study (homogeneous globules: two overlapped stars, heterogeneous globules: two separated stars less Fe-rich than the other two), triangles: Rattlesuake Hill basalts (Philpotts and Doyle 1983), ovals: andesites from Usu Volcano, Japan, and Steinerne Mann, Germany (Philpotts 1981), lozenges: Hawaiian tholeiites (Philpotts 1982), circles and inverted triangles: lunar basalts (Roedder and Weiblen 1971, 1972), semicircles: lunar basalts (Hess et al. 1975), diamonds: experimentally produced immiscible Skaergaard liquids (McBirney and Nakamura 1974), squares: experimentally produced immiscible liquids from a 1:1 mixture of jotunite and quartz mangerite (Philpotts 1981)
Heterogeneous globules show a larger compositional variation than homogeneous globules (Table 1). For example, one heterogeneous globule (column 3) has lower $\mathrm{Ti}$ and higher Si contents than the other (column 4). Energydispersive spectra across the former globule show that $\mathrm{Ti}$ is concentrated outside the area from which the AEM analysis was obtained, which is consistent with the TEM observations that the heterogeneity is associated with the presence of crystallites inside the globule. The nature of this heterogeneity can be further evaluated by comparing the individual analyses of heterogeneous and homogeneous globules. The $\mathrm{Fe}$ contents of heterogeneous globules are considerably lower than those in the homogeneous ones, indicating fractionation of $\mathrm{Fe}$ within the heterogeneous globules. The crystallization of magnetite may be largely responsible for this fractionation, which results in enrichment of $\mathrm{Si}, \mathrm{Al}$, and $\mathrm{K}$ in the center of the heterogeneous globule from which AEM analyses were obtained. The $\mathrm{Ca}$ and $\mathrm{P}$ contents in heterogeneous globules are also distinctly higher than those in homogeneous ones, indicating that apatite is another possible crystalline phase. The Ti contents in heterogeneous globules are highly variable, and Ti may form ilmenite or rutile.

One of the two analyses on matrix glasses (column 5) is very close to that of many other high-Si glasses (McBirney and Nakamura 1974; Philpotts 1981, 1982; Philpotts and Doyle 1983), whereas the other has relatively high $\mathrm{Al}$, $\mathrm{Ca}, \mathrm{Na}, \mathrm{K}$, and $\mathrm{Fe}$ and low Si contents. The high $\mathrm{Al}$ and $\mathrm{Ca}$ associated with low $\mathrm{Si}$ indicates that the latter analysis is contaminated mainly by the adjacent plagioclase. The analysis in column 5 is, therefore, suggested to be representative of the matrix glass chemistry.

The immiscible glass compositions obtained from this study and from microprobe analyses in the literature are compared in Fig. 5. The most pronounced difference from this comparison is that the globules in the present study are relatively $\mathrm{Fe}$-rich and Si-poor, resulting in a larger compositional difference than that defined by other data and by the immiscibility gap.

\section{Concentration gradients near the globules}

The evaluation of concentration gradients across the phase boundaries is essential for determining the rate-controlling process of phase transformation. With the AEM technique, a spatial resolution of 0.05 micron can be obtained for point analysis, which is uniquely suitable for detecting such gradients near small particles such as high-Fe globules. In the present case, however, such measurement is not straightforward, as contamination from small globules is very difficult to avoid; the concentration gradient near a given globule may be disturbed by other nearby globules, and an area with uniform thickness is necessary for consistent analyses. Figure 6 presents the best result from our efforts. Increase in $\mathrm{Al}$ and decrease in $\mathrm{Fe}, \mathrm{Ca}$, and $\mathrm{K}$ relative to $\mathrm{Si}$ in the matrix glass next to the globule are clearly shown, whereas no concentration gradients within the homogeneous globule can be defined. The enrichment of Al near the globule is expected, because Al concentration is higher in matrix glass than in globule; the opposite is true for $\mathrm{Fe}$ and $\mathrm{Ca}$. The depletion of $\mathrm{K}$ near the $\mathrm{K}$-poor globule is consistent with the behavior of alkali diffusion in silicate systems (Sato 1975).

No comparable analyses can be made closer than 0.05 micron from the interface, because this region is significant- 

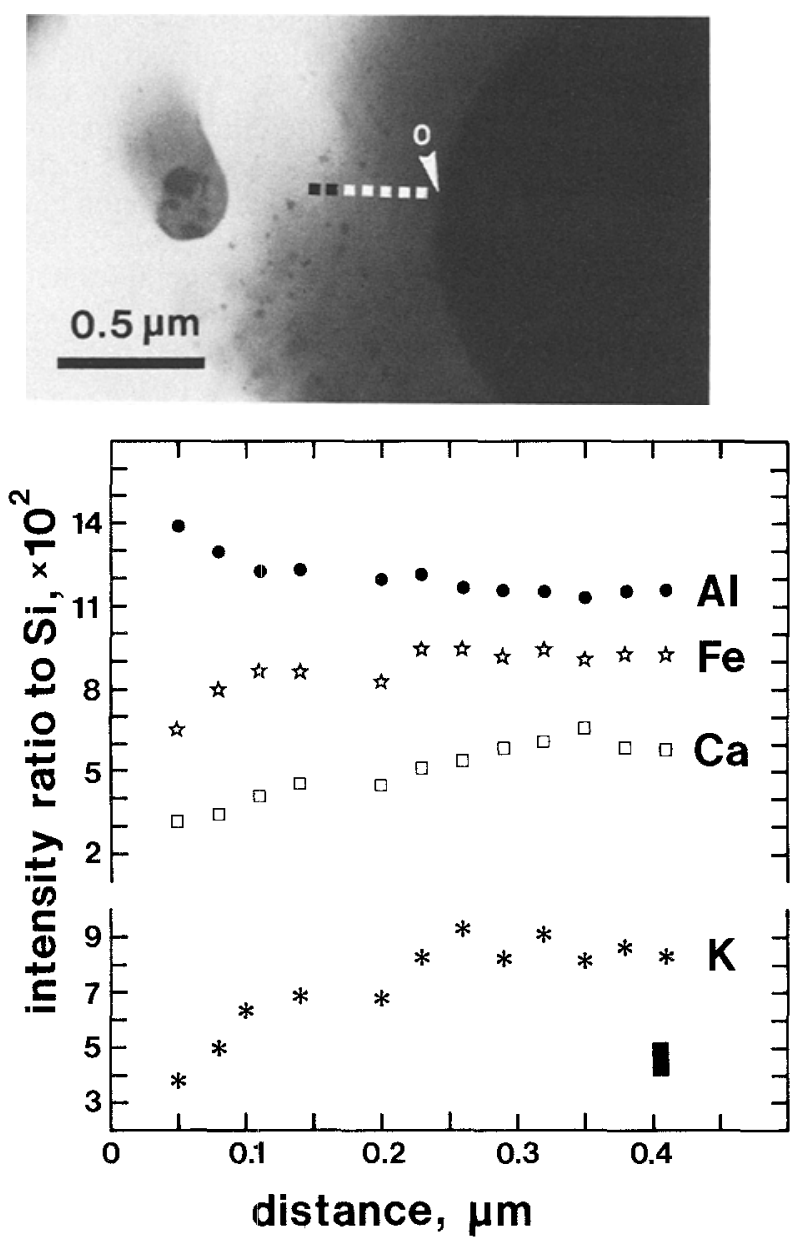

Fig. 6. Concentration gradients for $\mathrm{Al}, \mathrm{Fe}, \mathrm{Ca}$, and $\mathrm{K}$ in the matrix glass adjacent to a large globule (1.6 micron across). The traverse is indicated by the dotted line in the photograph, with the interface marked by 0 . The solid rectangle at the lower right indicates the range of uncertainties in peak-area measurement and distance for each point analysis

ly thicker than the outer region (count rate $300 \mathrm{cps}$ versus $70 \mathrm{cps}$ ). Therefore, interface compositions and, consequently, partition coefficients at the interface cannot be determined with reasonable certainty. In addition, no attempt has been made to assess other information related to diffusion because the concentration profiles may be modified by other nearby diffusion regimes (for example, note the other smaller globule to the left of the traverse in Fig. 6).

\section{Discussion}

\section{Origin of liquid immiscibility}

There are two major types of liquid-liquid phase separation in silicate systems: those caused by nucleation and those by spinodal decomposition (Doremus 1973). In a spinodal regime, phase separation is driven by small chemical fluctuation in the originally one-phase melt which lowers the free energy of the system, namely

$\Delta G=G^{\prime \prime} C_{0}(\Delta C)^{2}$

(Shewmon 1969), where $\Delta G$ is the change in free energy; $G^{\prime \prime}$ is defined as $\mathrm{d}^{2} G / \mathrm{d} C^{2}$ and is negative in the spinodal region; $C$ is composition; $C_{0}$ is the bulk composition; and $\Delta C$ is the fluctuation of composition. Because increase in $\Delta C$ further lowers the free energy of the system, spinodal decomposition is characterized by the formation of two structurally similar domains with similar volumes, with the dimensions of the domains related to the rate of diffusion of the components. Because the compositions in both domains vary continually, there is no definable boundary between the two phases during the process of decomposition. The compositions in both domains vary with time, and concentration gradients are present in both domains until a final equilibrium is attained.

Nucleation, on the other hand, involves the formation of nuclei of the thermodynamically stable (or, in some cases, metastable) phase from the parental melt (Kirkpatrick 1981). These nuclei, with definitive chemistry and structure and thus boundary, are initially very small in volume and amount and will grow or disappear through time. Unless the nuclei are formed from a melt with identical composition, a concentration gradient must develop in the parental melt near the interface of a growing nucleus. Because of its high surface-to-volume ratio, a nucleus becomes stable only after a critical size is reached. According to classical nucleation theory, the critical size is a function of supercooling and the surface energy of the nucleus. In liquid-liquid phase separation, the nuclei formed must be spherical, because it is the most stable configuration.

In the present case, the globules are spherical and have various sizes, the concentration gradients are present in the matrix glass but absent in the homogeneous globules, the distinctly different chemistries of globules and matrix glass suggests diverse structures of these phases. All these clearly indicate that the immiscibility occurs by nucleation of highFe globules from an originally homogeneous melt.

\section{Controlling factors of silicate liquid immiscibility}

The premise for the onset of immiscibility is the presence of two free energy minima in a given system. Most igneous melts can be considered as mixtures of $\mathrm{SiO}_{2}$ and metal oxide molecules, and the thermodynamic properties in such systems can be approximated by an ideal mixing model. The dominant reaction in the mixing process is

$\mathrm{O}^{0}+\mathrm{O}^{2-}=2 \mathrm{O}^{-}$

(Hess 1977), where $\mathrm{O}^{0}, \mathrm{O}^{2-}$, and $\mathrm{O}^{-}$are bridging, free, and nonbridging oxygens, respectively. The equilibrium constant for this reaction is

$k=\left[\mathrm{O}^{0}\right]\left[\mathrm{O}^{2-}\right] /\left[\mathrm{O}^{-}\right]^{2}$.

Charles (1969) demonstrated that in most silicate systems, the entropy of mixing as a function of metal oxide fraction has two maxima only for $0<k<0.01$, whereas the enthalpy of mixing as a function of metal oxide fraction takes the form of a smooth, U-shaped curve. This indicates that immisicibility can occur only in melts with low $\mathrm{k}$ values, which correspond to those with chains of silica tetrahedra as dominant structural units (i.e., high concentration of nonbridging oxygens). No immiscibility can be expected in highly siliceous or highly metalliferous melts, because the concentrations of bridging and free oxygens, respectively, are too high. Orthosilicate melts (those composed dominantly of isolated silica tetrahedra) also do not have immiscibility fields, because $k$ approaches zero. 


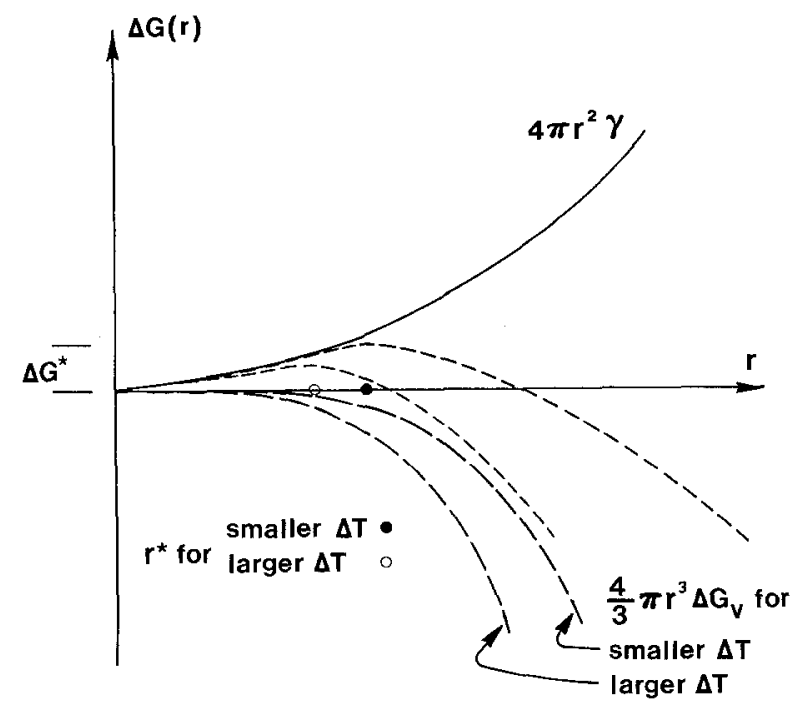

Fig. 7. The relationship between energy barrier for nucleation $(\Delta G(r))$ and size of the embryo $(r)$ at two supercoolings $(\Delta T)$. The total energy barrier (short-dash curves) is composed of a volume energy $\left(4 \pi r^{3} \Delta G_{v} / 3\right.$, where $\Delta G_{v}$ is the difference between the free energy of the nucleus at a given supercooling and at equilibrium per unit volume) and a surface energy (solid curve) term. The amount of $\Delta G^{*}$ is indicated for the case of smaller supercooling. Note that for both supercoolings $A G(r)$ first increase until the critical sizes, $r^{*}$, are reached and then decrease. In classical nucleation theory $\Delta G^{*}$ is proportional to $\gamma^{3} /(\Delta T)^{2}$ and $r^{*}$ to $\gamma / \Delta T$

In this context, the occurrence and extent of immiscibility is controlled by the factors which control the melt structure. The most important factor, therefore, is the nature and abundance of metallic ions ionic strengths (referred to as network-modifying cations (NMCs), such as $\mathrm{Mg}, \mathrm{P}$, $\mathrm{S}, \mathrm{Cl}, \mathrm{Ca}, \mathrm{Ti}, \mathrm{Fe}^{2+}$, and $\mathrm{Fe}^{3+}$ ) (Mysen et al. 1982) and other factors influencing the speciation of these cations (for example, oxygen fugacity which buffers the $\mathrm{Fe}^{3+} / \mathrm{Fe}^{2+}$ ratio). Aspects of the roles of these factors on silicate liquid immiscibility have been experimentally investigated and discussed (Hess 1980; Naslund 1983). It should also be noted that the theory developed by Charles (1969) is based on the assumption of ideal mixing behavior of the melt, whereas a regular solution model (Ghiorso and Carmichael 1980) might be more suitable for thermodynamic modelling of the mixing behavior in igneous melts.

\section{Mechanisms of silicate liquid immiscibility}

It has been demonstrated in the previous section that immiscibility most likely occurs in melts composed mainly of chains of silica tetrahedra, and that immiscibility results in two liquids having higher and lower degrees of polymerization, respectively, than that of the parental melt. The physical process responsible for such changes in melt structure can be expressed by an example:

$$
\underset{\text { chain }}{3 \mathrm{Si}_{2} \mathrm{O}_{6}^{2-}}+\underset{\mathrm{NMC}}{\mathrm{Ti}^{4+}}=\underset{\text { framework }}{5 \mathrm{SiO}_{2}}+\underset{\text { monomers }}{\mathrm{SiO}_{4}^{4-}+\mathrm{TiO}_{4}^{4-}}
$$

(Mysen et al. 1982). The essential mechanism in such a reaction is the release of part of the nonbridging oxygens from the chain units to form NMC and silica monomers, with the chain units turning into framework units by sharing the rest of the nonbridging oxygens. It is therefore necessary that the NMCs have high ionic strengths to incorporate the nonbridging oxygens. Cations with low ionic strengths (such as $\mathrm{K}$ and $\mathrm{Na}$ ) are unable to do so, and thus are retained in the highly polymerized structure. The physiochemical result of such reactions is the separation of a melt composed dominantly of NMC and silica monomers (highly depolymerized) from the parental melt, leaving behind the melt consisting mainly of three-dimensional framework of silica and alumina tetrahedra with interstitial cations with low ionic strengths (highly polymerized).

\section{Conditions for the formation of immiscible glasses in Umtanum basalts}

As mentioned earlier, the AEM data plot considerably outside the field of stable immiscibility proposed by Naslund (1983). Freestone (1978) found that the addition of 1 mole percent $\mathrm{P}_{2} \mathrm{O}_{5}$ and 3 mole percent $\mathrm{TiO}_{2}$ to the system fayalite-leucite-silica at $\mathrm{fO}_{2}=10^{-15.2}$ yields an immiscibility gap significantly wider than that obtained by Roedder (1951). However, Naslund (1983), by adding various amounts of $\mathrm{Ca}, \mathrm{Al}, \mathrm{Mg}, \mathrm{P}, \mathrm{Ti}$, and $\mathrm{Mn}$ to the system $\mathrm{KAlSi}_{3} \mathrm{O}_{8}-\mathrm{FeO}-$ $\mathrm{Fe}_{2} \mathrm{O}_{3}-\mathrm{SiO}_{2}$ at $\mathrm{fO}_{2}=10^{-0.7}$, found that these cations have various effects on the extent of immiscibility: $\mathrm{Ca}$ and $\mathrm{Mg}$ appreciably narrow the gap, whereas $\mathrm{Ti}, \mathrm{Mn}$, and $\mathrm{P}$ shift the gap towards the high-Si side of the join $\mathrm{SiO}_{2}-\mathrm{MO}$ (where $\mathrm{M}$ represents $\mathrm{NMCs}$ ). The low-Si end of the gap reaches the position indicated by AEM analysis (around $30 \mathrm{wt} \%$ $\mathrm{SiO}_{2}$ in Fig. 5) only at $\mathrm{fO}_{2}=10^{-5}$ (Naslund 1983), which is too oxidized for natural basalts (on the other hand, see Freestone and Powell (1983) for different results). Because the NMCs have nonadditive effects on the extent of immiscibility, Naslund's results indicate hat the size of the immiscibility gap will not change much for natural basaltic melts from that shown in Fig. 5. It follows that the compositions of the homogeneous globules and matrix glasses represent those on the metastable extension of the limbs of the immiscibility solvus, indicating that the liquid immiscibility in the Umtanum basalt occurred at temperatures lower than those for the stable immiscibility, and that the globules were nucleated from the parental melt under supercooled conditions. The maximum supercooling along the join defined by the Umtanum immiscible glass compositions in the system leucite-fayalite-silica is about $160^{\circ} \mathrm{C}$, whereas the corresponding temperature range for stable immiscibility is about $50^{\circ} \mathrm{C}$ (Visser and Koster van Groos 1979).

Given a melt at a supercooling $\Delta T$ (defined as $\left.T_{\text {liquidus }}-T_{\text {actual }}\right)$, the formation of nuclei is initially associated with an energy barrier which is a function of supercooling, the surface energy of the nuclei $(\gamma)$, the volume free energy of the nuclei $\left(\Delta G_{v}\right)$, and the size of the nuclei (Fig. 7). The energy barrier is larger for larger nuclei until a maximum energy, $\Delta G^{*}$, is reached, with a corresponding size $r^{*}$, called critical radius, of the nuclei. Beyond this point, further growth of the nuclei lowers the free energy of the system, thus the nuclei become stable, and crystal (or liquid) growth occurs. For nuclei smaller than $r^{*}$ (often called embryos), however, there is a much higher probability for these embryos to shrink than grow, and thus the successful development of a nucleus with a size larger than $r^{*}$ is entirely fortutious.

The size distribution of the embryos during the incipient stage of nucleation has been developed by Volmer and Weber and subsequently modified by Becker and Doring 
(see Christian (1975) for comprehensive discussions). The theory of Becker and Doring may be expressed as

$N_{r}=N \exp (-\Delta G(r) / k T)$

(Kashchiev 1969), where $N_{r}$ is the number of the embryos with a size $r, N$ is the number of molecules in the system, $\Delta G(r)$ can be expanded as

$\Delta G(r)=\Delta G^{0}-k T \Omega r+b r^{2 / 3}$

where $\Delta G^{0}$ is the standard free energy for nucleation, $k$ is the Boltzmann constant, $T$ is temperature, $\Omega$ is a measure of supersaturation of the system, and $b$ is a constant. It follows that, at a certain supercooling, the plot of $\log N_{r}$ against $r$ should be a straight line with a negative slope for small embryos. That slope becomes more negative when $r^{*}$ is approached, because the theory of Becker and Doring assumed an equal probability for the nuclei with a size $r^{*}$ to shrink and to grow. Figure 3 shows, however, that the linear correlation between $\log N_{r}$ and $r$ exists only for the 0.3- to 0.8-micron globules. Both smaller and larger ones are more abundant than predicted for isothermal conditions. At larger $\Delta T$ (i.e., lower $\mathrm{T}$ ), however, $\Delta G^{*}$ becomes smaller, and the medium-sized embryos formed at higher temperatures become unstable, because they have higher values of $\Delta G(r)$ (Fig. 7); they must either shrink back to smaller embryos or grow into larger ones. This redistribution of embryo population upon continual temperature decrease results in much more abundant smaller embryos and relatively less abundant larger ones, because a much greater material supply is needed to grow a larger embryo, and only the ones which grow fast and large enough can become stable. We suggest, based on Fig. 3, that the nucleation of the globules in the parental melt occurred over a period of cooling. Only the globules larger than about 0.7 micron are truly stable nuclei; those smaller than 0.7 micron are unstable embryos. The presence of concentration gradients near the globule-matrix glass interface (e.g. Fig. 6) clearly indicates the diffusion-controlled growth of large globules.

We also propose that, during this period of cooling, nucleation and growth of NMC-rich phases (magnetite, ilmenite, apatite, rutile, and perhaps others) results in slightly Si-rich residual liquids with optical and chemical heterogeneity in some stable globules. It is expected that not all the stable globules would crystallize because nucleation is a random process.

The globules in this study tend to be smaller and more NMC-rich relative to those from many published studies (Fig. 5). For globules grown under near-equilibrium conditions, the convexity of the immiscibility solvus dictates that they should become progressively NMC-rich upon growth, thus larger globules should also have higher NMC contents. On the other hand, under moderately supercooled conditios, the nucleation rates become higher but growth rate lower with increasing supercooling, hence the globules formed at higher supercooling (lower temperature) should be more numerous and more NMC-rich but statistically smaller in size. The consistency between the latter intepretation and the present observation, therefore, indicates that the chemical diversity between high-NMC and high-Si liquids is likely to be a function of supercooling under otherwise similar conditions. Moreover, skeletal or dendritic magnetites, which indicate disequilibrium crystallization (Kirkpatrick 1981), are associated exclusively with immiscible glasses in most natural basalts (Philpotts 1982).
Hence, although subjected to debate (Biggar 1979 vs. Philpotts and Doyle 1980), the effects of supercooling on the nature of liquid immiscibility should be investigated in further detail.

Acknowledgements. This paper represents part of the results from the mineralogical studies on backfill performance for high-level nuclear waste disposal. We are indebted to Drs. Donald Alexander (U.S. Nuclear Regulatory Commission) and Art White (Lawrence Berkeley Laboratory, University of California at Berkeley) for their valuable suggestions and assistance during the course of this study, and to the technical crew in the Electron Microbeam Analysis Laboratory (University of Michigan) for their efforts in maintaining the TEM facilities. The paper has benefitted from the reviews of Drs. Paul Cloke, Bernard Evans, and Anthony Philpotts. Financial support was made by a grant from the Argonne National Laboratory (Contract No. 31-109-38-6944).

\section{References}

Allard LF, Blake DF (1982) The practice of modifying an analytical electron microscope to produce clean X-ray spectra. In: Heinrich KFJ (ed) Microbeam Analysis 1982, San Francisco Press, San Francisco, California, 8-19 pp

Biggar GM (1979) Immiscibility in tholeiites. Mineral Mag $43: 543-544$

Blake DF, Issacs AM, Kushler RH (1983) A statistical method for the analysis of quantitative thin-film X-ray microanalytical data. J Microse 131:249-255

Burnett DG, Douglas RW (1970) Liquid-liquid phase separation in the soda-lime-silica system. Phys Chem Glasses $11: 125-135$

Charles RJ (1969) The origin of immiscibility in silicate solutions. Phys Chem Glasses 10:169-178

Christian JW (1975) The Theory of transformations in metals and alloys, part I. Equilibrium and General Kinetic Theory (2nd ed), Pergamon Press, $586 \mathrm{p}$

Cliff G, Lorimer GW (1975) The quantitative analysis of thin specimens. J Microsc 103:203-207

Craw D (1981) Oxidation and microprobe-induced potassium mobility in iron-bearing phyllosilicates from the Otago schists, New Zealand. Lithos 14:49-57

Doremus RH (1973) Glass science, Wiley, New York, $349 \mathrm{p}$

Freestone IC (1978) Liquid immiscibility in alkali-rich magmas. Chem Geol 23:115-123

Freestone IC, Powell R (1983) The low temperature field of liquid inmiscibility in the system $\mathrm{K}_{2} \mathrm{O}-\mathrm{Al}_{2} \mathrm{O}_{3}-\mathrm{FeO}-\mathrm{SiO}_{2}$ with special reference to the join fayalite-leucite-silica. Contrib Mineral Petrol 82:291-299

Ghiorso MS, Carmichael ISE (1980) A regular solution model for met-aluminous silicate liquids: applications to geothermometry, immiscibility, and the source regions of basic magmas. Contrib Mineral Petrol 71:323-342

Goldstein JI (1979) Principles of thin-film X-ray microanalysis. In: Hren $\mathrm{JJ}$ et al. (eds) Introduction to analytical electron microscopy, Plenum, New York, p 83-120

Goldstein JI, Castley JL, Lorimer GW, Reed SJB (1977) Quantitative X-ray microanalysis in the electron microscope. SEM Inc 1977. In: Johari O (ed) IITRI Chicago III 1:315-324

Hess PC (1977) Structure of silicate melts. Can Mineral 15:162-178

Hess PC (1980) Polymerization model for silicate melts. In: Hargraves RB (ed) Physics of magmatic processes, Princeton University Press, Princeton, New Jersey, pp 3-48

Hess PC, Rutherford MJ, Guillemette RN, Ryerson FJ, Tuchfield HA (1975) Residual products of fractional crystallization of lunar magmas: an experimental study. Proc 6th Lunar Sci Conf $1: 895-909$

James PF, McMillan PW (1970) Quantitative measurements of phase separation in glasses using transmission electron microscopy. Part 2, a study of lithia-silica glasses and the influence of phosphorus pentoxide. Phys Chem Glasses 11:64-70 
Kashchiev D (1969) Nucleation of existing cluster size distributions. Surf Sci 18:389-397

Kirkpatrick RJ (1981) Kinetics of crystallization of igneous rocks. In: Lasaga AC, Kirkpatrick RJ (eds) Kinetics of geochemical processes. Mineral Soc Am 8:321-398

Knipe RJ (1979) Chemical analyses during slaty cleavage development. Bull Mineral 102:206-210

Levin EM (1970) Liquid immiscibility in oxide systems. In: Alper AM (ed) Phase Diagrams: Materials science and technology, vol V, Academic Press, New York, pp 143-236

Lorimer GW, Cliff G (1976) Analytical electron microscopy of minerals. In: Wenk H-R (ed) Electron microscopy in mineralogy, Springer, Berlin Heidelberg New York, pp 506-519

McBirney AR, Nakamura Y (1974) Immiscibility in late-stage magmas of the Skaegaard intrusion. Carnegie Inst Washington Yearb 73:348-352

Myers CW, Price SM, and others (1979) Geologic studies of the Columbia plateau: a status report. Rockwell Hanford Operations Report RHO-BWI-ST-4

Mysen BO, Virgo D, Seifert FA (1982) The structure of silicate melts: implications for chemical and physical properties of natural magma. Rev Geophys Space Phys 20:353-383

Naslund HR (1983) The effect of oxygen fugacity on liquid immiscibility in iron-bearing silicate melts. Am J Sci 283: 1034-1059

Ohlberg SM, Hammel JJ (1965) Formation and structure of phase separated soda-lime-silica glass. 7th International Congress Glass, Brussels, Belgium

Philpotts AR (1979) Silicate liquid immiscibility in tholeiitic basalts. J Petrol 20:99-118

Philpotts AR (1981) A model for the generation of massif-type anorthosites. Can Mineral 19:233-253

Philpotts AR (1982) Compositions of immiscible liquids in volcanic rocks. Contrib Mineral Petrol 80:201-218
Philpotts AR, Doyle CD (1980) Immiscibility in tholeiites: a discussion. Mineral Mag 43:939-940

Philpotts AR, Doyle CD (1983) Effect of magma oxidation state on the extent of silica liquid immiscibility in a tholeiitic basalt. Am J Sci 283:967-985

Roedder EW (1951). Low-temperature liquid immiscibility in the system $\mathrm{K}_{2} \mathrm{O}-\mathrm{FeO}-\mathrm{Al}_{2} \mathrm{O}_{3}-\mathrm{SiO}_{2}$. Am Mineral 36:282-286

Roedder E (1979) Silicate liquid immiscibility in magmas. In: Yoder HS Jr (ed) The evolution of the igneous rocks, Princeton University Press, Princeton, New Jersey, pp 15-57

Roedder E, Weiblen PW (1971) Petrology of silicate melt inclusions, Apollo 11 and Apollo 12 and terrestrial equivalents. Proc 2nd Lunar Sci Conf 1:507-528

Roedder E, Weiblen PW (1972) Silicate melt inclusions and glasses in lunar soil fragments from the Luna 16 core sample. Earth Planet Sci Lett 13:272-285

Sato H (1975) Diffusion coronas around quartz xenocrysts in andesite and basalt from Tertiary volcanic region in northern Shikoku, Japan. Contrib Mineral Petrol 50:49-64

Shewmon PG (1969) Transformations in metals. McGraw-Hill, New York, p 394

Visser W, Koster van Groos AF (1979) Phase relations in the system $\mathrm{K}_{2} \mathrm{O}-\mathrm{FeO}-\mathrm{Al}_{2} \mathrm{O}_{3}-\mathrm{SiO}_{2}$ at 1 atmosphere with special emphasis on low temperature liquid immiscibility. Am J Sci 279:70-91

Zaluzec NJ (1979) Quantitative X-ray microanalysis: instrumental considerations and applications to material science. In: Hren $\mathrm{JJ}$ et al. (eds) Introduction to analytical electron microscopy, Plenum, New York, p 121-167

Received May 7, 1984 / Accepted April 28, 1986 